InterAção | 13

\title{
CONFLITOS NO MEDITERRÂNEO
}

\section{Federico Aznar Fernández-Montesinos}

O Mediterrâneo ocupa um espaço central na maioria das representações do mundo, próprias da cultura ocidental (mapas, etc...), particularmente nas européias. Assim, não é um paradoxo o significado dos nomes que se deram aos grandes berços das civilizações do mundo; o Mediterrâneo, literalmente o mar no meio da terra, situado no paralelo da China, o império do meio; a Península Ibérica e a Turquia, cadinhos de outras culturas, marcam seu eixo axial. E, citando Platão em Fédon, "há muitos homens em outras partes que vivem em lugares semelhantes. É que por toda a Terra há muitas concavidades, de formas e tamanhos variáveis, para as quais converge água, vapor e ar".

Mas o Mediterrâneo não é só um espaço físico como Platão também indicava "nós outros, moradores da região que vai do Fásis às Colunas de Hércules, ocupamos uma porção insignificante da terra, em torno do mar, à feição de formigas e rãs na beira de um charco", mas também cultural; os seus limites oscilam dependendo do aspecto considerado. Portugal é um país mediterrâneo, como é o Cáucaso e o Irã. Há nele muito de vontade.

No entanto, o peso do Mediterrâneo diminuiu, mesmo dentro da Europa; seu centro de gravidade econômico se deslocou para o norte; assim, por exemplo, os três principais portos europeus já são atlânticos. Desse modo, deixa seu papel de berço e de centro para se tornar em fronteira com o outro mundo, cujas raízes se instalam em suas margens; e nele convergem as três grandes civilizações da casa de Abraão (o Islã 
14 | InterAção

se auto define como Millet Ibrahim, a religião de Abraão). A História converteu-o em berço, união e fronteira ao transformar sucessivamente seu papel, reforçando alguns dos seus atributos.

É surpreendente a observação de como, depois de séculos de esforço para conseguir a liberdade dos mares, o Mediterrâneo, mar de ligação e de intercambio ao longo da história, passou a ser percebido como um acidente geográfico que, como material dielétrico, isola os pólos com a maior diferença de potencial de desenvolvimento do mundo; a diferença de renda per capita entre suas margens é de 15 para 1.

E se por séculos o Mediterrâneo uniu culturas, agora se tornou o foco onde convergem conflitos econômicos, políticos e até de civilização, contribuindo para a formação e o afastamento de mundos construídos de forma autônoma. A margem norte tem sido sacudida por uma crise econômica de grandes proporções, mas a crise da margem sul, que alguns chamam de primaveras, abalou as bases de sua cultura.

\section{Religião e Cultura como pontos fundamentais dos conflitos no Medi- terrâneo.}

O Islã é uma religião que reúne diferentes culturas em todo o planeta. A diversidade do Islã e o seu multiculturalismo já tiveram reflexos entre os companheiros do profeta Maomé, que admitiram em seu seio e trataram como iguais a Salman, o Persa, ou a Bilal, que havia sido um escravo negro alforriado; "ouvi e obedecei, mesmo que tivésseis como chefe um escravo da Abissinia, cuja cabeça fosse como uma uva passa”.

O Islã não é monolítico; é pluralismo, diversidade e diferença. 
O pluralismo das sociedades islâmicas é prova de que foi possível a coexistência com os não crentes, isso sim, desde que se submetessem à autoridade do Islã.

O Alcorão também é diferença porque permite distintas visões do livro sagrado, abordagens diversas para a religião, sem uma hierarquia que possa fixar uma doutrina oficial, a verdade. E é diversidade pelas diferentes culturas que estão associadas à religião, como resultado da extensão geográfica de sua área de domínio. A diversidade e a diferença se articulam no âmbito de uma sociedade que pretende ser igualitária.

\subsection{Cultura e Poder}

As culturas têm um sistema de valores completo, único, fechado, um modo de ver o mundo, que não é constante ao longo do tempo, mas que varia em cada momento. Os valores são praticamente os mesmos, sem grandes alterações: o que varia em cada uma das culturas é a sua priorização.

Assim, para o Ocidente o eixo de referência é o indivíduo, enquanto que para o mundo islâmico o eixo é a comunidade, a Ummah. Ainda mais, para o Ocidente do século XXI o primeiro dos valores a ser considerado é sem dúvida a liberdade, embora nem sempre tenha sido assim (a liberdade de pensamento é uma concepção iluminista). No entanto, para muitos muçulmanos é a justiça. E a partir daí, se estivéssemos num espaço unidimensional, estariam em uma ordem de prioridade diferente todos os demais. Trata-se, como foi dito, de um sistema. Assim, a existência de uma palavra sem tradução direta para outro idioma é uma expressão dessa desigualdade quanto ao or- 
16 | InterAção

denamento de valores.

Com cada um dos sistemas de valores se faz uma abordagem do mundo, de seus problemas e se tomam decisões. Compreende-se a simplificação por sua plasticidade, é diferente a abordagem que se faz e as decisões que consequentemente são tomadas, considerando em primeiro lugar a liberdade, ao invés de considerar como primeiro valor a preservar a igualdade ou a justiça (com a liberdade teríamos o modelo liberal do século XIX; considerando a igualdade, as democracias populares; e intercalando liberdade, igualdade e justiça, o Estado Social e Democrático de Direito).

O etnocentrismo apresenta-se como algo natural e lógico, transparente ao usuário, enquanto o alheio é estranho, extravagante, quando não uma agressão. Acrescente-se a isso que a lógica do mundo ocidental é racional cartesiano, enquanto o resto não é necessariamente assim.

O resultado é que uma cultura constituída sobre um sistema de valores, ao qual se sobrepõem estruturas de poder construídas umas sobre outras, com as quais não se consegue um encaixe perfeito, aparecendo constantes atritos e tensões. A cultura transforma o poder e o poder transforma a cultura. E a cultura e os movimentos sociais são sempre mais fortes, o que não significa que o resultado seja, entre outras coisas, uma crise de identidade.

\subsection{Problemas do desenvolvimento pós colonial}

Por outro lado, devem-se considerar os sucessivos fracassos que têm atingido os regimes autoritários pós coloniais que foram impostos em muitos países árabes e que propuseram alternativas, desde 
InterAção | 17

o laicismo ao desenvolvimento econômico (como as "indústrias de industrialização" argelinas); a chamada via socialista árabe, finalmente levou a uma crise econômica, social, habitacional, sanitária, que conduziu ao desemprego, ao subemprego e à emigração de jovens (mais de $70 \%$ das populações têm menos de 35 anos), assim como a uma perda de confiança em soluções alternativas.

Além disso, as políticas sociais apoiadas pela ajuda e pelo comércio com o Ocidente não puderam resistir à crise econômica mundial, como se deduz da simples observação dos relatórios do PNUD; a diminuição desses recursos pode ser considerada como o detonante das Primaveras Árabes, como ocorreu nos anos oitenta com "as revoltas da farinha", processo semelhante ao atual - embora de intensidade diferente -, causado naquela época pela elevação dos preços dos gêneros de primeira necessidade e pela diminuição das receitas provenientes do petróleo.

Acrescente-se a isso o problema da corrupção, que tem um inegável componente cultural (no sistema Makhzen se exige uma gorjeta), e da transmissão patrimonial do poder. Há países que desde a independência não haviam realizado uma troca de poder; as democracias autoritárias em fase de substituição de poder - Egito, Líbia - resistiram mal aos protestos, mas as monarquias, somente se ressentiram. E toda fase de transição, por pacífica que seja, enfraquece o poder e torna-o vulnerável.

Junte-se também a existência de estruturas sociais pré-estatais (clãs, tribos), cujos limites, não coincidem com os do Estado, que, em alguns casos, somente se aglutinaram na luta pela descolonização (Argélia se consolidou como país em uma luta que uniu suas 805 
18 | InterAção

tribos) ou simplesmente não se uniram, o que requer complexos e oscilantes equilíbrios entre os diversos interesses dos grupos.

O resultado é a incapacidade do Estado em resolver essas questões, sua principal função, levando à sua deslegitimação e criando grandes áreas de exclusão social. O poder tem sido exercido com o uso de um forte aparato policial, quando não pelo emprego das Forças Armadas, convertidas em árbitros da situação. Isso tem eliminado qualquer dissidência, qualquer ajuste, mas seu uso não impediu as grandes comoções, gerando o debate entre a imobilidade e a revolução.

Paralelamente, a falta de uma oposição organizada e a heterogeneidade dos grupos parece conduzir a luta em duas etapas e dão mais incerteza ao resultado final, com o risco de uma nova guerra civil. Um primeiro passo procuraria abolir o regime em vigor e uma segunda etapa procuraria estabelecer a representação dos diferentes grupos, bem como das idéias que eles defendem.

Os apelos por mais democracia são acima de tudo uma chamada desesperada à solução desses problemas por qualquer meio; o que se pretende conseguir é simplesmente o pão (o processo é paralelo ao aumento dos preços dos produtos básicos), por mais que se utilizem fórmulas mais ou menos transcendentes para articular a demanda e inovações como redes sociais e telefones celulares para a ativação de movimentos (na verdade um espaço imaterial que se encaixa muito bem no conceito místico da Ummah).

A conseqüência dessa falta de expectativa tem sido a busca de modelos alternativos, ainda mais quando se declaram a solução do problema e contam com a legitimidade adicional de terem sido opositores de um regime ineficiente; além disso, a falta de uma oposição 
InterAção | 19

organizada coloca o debate no plano laico/religioso (no Ocidente a maioria dos debates são profanos e dão muito de si por mais que se fale sobre o final das ideologias).

Como resultado, a posição inicialmente laica desses movimentos deu lugar, de forma natural, a movimentos islâmicos que foram colocados nos corredores do poder pelas mãos de processos eleitorais. E essa é a solução ofertada a partir de sua cultura, quando as discussões são apresentadas em termos dicotômicos e o outro lado da equação tenha falhado.

Acrescente a isso o apoio especial que se dá a esse tipo de organizações; algumas grandes fortunas ligadas ao negócio do petróleo, em resposta ao mandato islâmico da Sadaqa (esmola), tendo em vista a Dawa (pregação), e que promovem formulações muito estritas do Islã, que chocam, inclusive, com a sua concepção popular dominante.

O surgimento de sociedades islâmicas assistenciais, como a Frente Islâmica de Salvação (FIS) argelina, os Irmãos Muçulmanos ou a própria Hezbollah (literalmente o Partido de Deus), que complementam ou substituem exemplarmente o Estado e contribuem para a sua marginalização, é a prova de sua fragilidade. Mas esses movimentos populares, parcialmente desvertebrados, sob a égide de declarações como "O Alcorão é a nossa Constituição", incorporaram simultaneamente vários discursos contraditórios e mal resolvidos sobre questões fundamentais, como a própria democracia ou a economia de mercado.

\subsection{Islã político}

Do ponto de vista religioso, Maomé não se pronunciou so- 
bre qualquer forma específica de governo, mas fixou seus princípios motores. $\mathrm{O}$ governo tem uma natureza instrumental e não se trata da construção do reino de Deus no mundo. O Estado é um meio de garantir a realização de um propósito mais elevado, localizado na Outra Vida.

O poder do governante muçulmano tradicional é um poder limitado, como consequencia de sua fonte de autoridade limitada; é obrigado a respeitar e aplicar a Sharia e a cujo âmbito se encontra restrito: "O muçulmano tem que ouvir e obedecer, gostando ou não, a menos que uma transgressão seja ordenada, então nem ouve e nem obedece". Por isso, o governante não é um déspota, faz o que deve e não o que quer. Em contrapartida, o Alcorão estabelece uma obrigação de obediência: "obedecei aqueles que têm a autoridade", diz o verso do Alcorão dos Emirs.

Além disso, uma mera transgressão não desabilita o líder para o exercício do poder; como diz o hadith "deve-se rezar, mesmo que seja um transgressor". Nem desabilita seu caráter injusto, porque, como observou Ibn Taymiyya, o governo injusto é preferível ao tumulto: "Setenta anos de tirania é melhor do que uma noite de guerra civil" ou "quem abomina qualquer coisa de seu chefe, que seja paciente, porque aquele que tire um pingo da obediência ao poder morrerá como pagão".

No entanto, no sentido não-conformista, se manifestam outros hadiths: "não ajude a um tirano se você sabe que ele é assim", "apoiar a comunidade quando ela está errada é como cair num poço por estar preso à cauda de um camelo que está a ponto de cair" ou "quando um muçulmano é obrigado a cometer um pecado, não tem a obrigação de ouvir e nem de obedecer".

Resumindo, não há meios ou medidas que sirvam para articular a desobediência. Na verdade, a prática histórica mostra um espírito 
que tende à inação diante do tirano, desde que ele não viole os limites estabelecidos pela Sharia e se lhe impute uma patente impiedade. Isso não só justifica a rebelião da comunidade, mas se obriga a ela. E a autoridade no Islã é um acordo entre governante e comunidade, em que se articulam diferentes formas de controle e de limitação de poder.

Alguns fundamentalistas acreditam que o ponto em que o Islã e a democracia se compatibilizam se encontra na democracia islâmica, já que a concepção ocidental de democracia é modificada a partir de uma percepção religiosa; dessa forma, é liberada dos preconceitos próprios do Cristianismo, resultando um sistema de governo que consegue conciliar as liberdades políticas com a natureza religiosa do espaço público.

Dentro desse quadro, é possível a existência de partidos políticos e até de liberdade de imprensa, desde que, logicamente, se assuma e não se questione os princípios, valores e regras islâmicas. No entanto, a dificuldade está em definir o espaço religioso, que pode variar desde o laicismo ocidental à quase total regulamentação (há hadiths que indicam a forma correta de dormir). Para outros, sem exceções, a democracia é um conceito ocidental incompatível com as formas clássicas islâmicas, que estão perfeitamente articuladas.

O Islã político, como seu nome indica, trata de levar à área política os princípios e crenças do Islã tradicional; em princípio, uma teoria política parece ter muito em comum com a democracia cristã; a diferença pode estar em que os sistemas de governo e de administração pública mais avançados, incluindo o próprio Estado, têm sido criados segundo padrões de valores ocidentais, diferentes das formas tradicionais islâmicas de governo; procuram transformar, assim, as 
bases do sistema, algo que a democracia cristã não questiona. A desvantagem é uma politização da religião e de sua maior visibilidade, de modo que o plano religioso e transcendental seja um plano mais ativo de conflito.

O modo mais ou menos possibilista da proposta política, sua flexibilidade e jogo de cintura são fatores determinantes na realização de uma catalogação adequada e contribuem para sua distribuição espectral. $\mathrm{O}$ problema reside em distinguir o Islã do radicalismo islâmico, pelo difuso de seus limites. Ambos podem querer o mesmo e é muito difícil definir um como islâmico, por sua moderada reivindicação islâmica, e chamar outros de radical, embora, como disse Protágoras Samos, "O homem é a medida de todas as coisas, das que são como são e das que não são como não são".

Em vista dessas considerações e não esquecendo a proposta política desses movimentos, a classificação parece ser feita de acordo com a metodologia da ação proposta, com base em aceitar o sistema institucional e a aplicação ou não da violência, ou assumir seus objetivos.

Excluir uma idéia do jogo democrático, banir o que não gosta, é não articular um conflito; tais posições devem ser sempre tomadas com precaução, pois podem comprometer a legitimidade das instituições. Além disso, o choque com a realidade costuma ser o Termidor de todo movimento revolucionário e utópico, porque como diz o ditado, uma coisa é criticar e outra coisa é dar o trigo. Não se pode entender a exclusão permanente, às vezes, de mais de $60 \%$ da população.

E parece natural o fato de que uma sociedade profundamente religiosa se reflita em seus governantes e nas leis que a regem. É a re-islamização desde abaixo, de que falou Gilles Kepel. A questão 
InterAção | 23

é saber se o Ocidente pode aceitar um resultado nas urnas em favor dos islâmicos, de acordo com os princípios democráticos proclamados, mesmo que isso possa afetar os seus interesses ou inclusive a sua segurança.

Pelo contrário, não aceitá-los parece de alguma forma apoiar fórmulas autoritárias contrárias às crenças e essências ocidentais, que, aliás, já foi feito antes em nome da Segurança. O Ocidente se coloca, assim, frente às suas próprias contradições internas, embora deva ficar claro que aceitar uns resultados não obriga apoiar o governo que os obtêm, a não ser que esteja de acordo com suas políticas. Assim, há suspeitas de terrorismo sobre líderes políticos islâmicos próximos ao poder.

\section{Geografia dos conflitos Mediterrâneos}

Sem querer quebrar a natureza integral da área Mediterrânea, estudar-se-á o Magreb e os diferentes conflitos que coexistem no Oriente Médio, com ênfase especial sobre aqueles em que ocorreram as chamadas primaveras árabes (tão diferentes entre si), assumindo uma relativa calma no lado norte, mesmo no caso dos Bálcãs. É a MENA (Middle East and North Africa - Oriente Médio e Norte da África em inglês).

\subsection{Magreb}

A palavra Magreb significa literalmente "o ocidente" e integra cinco países: Marrocos, Argélia, Líbia, Mauritânia e Tunísia, Estados cujas consolidações foram favorecidas pelos processos de independência. No entanto, apesar de compartilhar etnias, história, cultura 
e religião, não estão sequer minimamente integradas, bastando dizer que o comércio entre eles não atinge 4\% do PIB e que não há infra-estruturas comuns. Além disso, embora formalmente formem parte da União do Magreb Árabe (UMA), que tem até uma cláusula de defesa mútua, isso, até agora, é algo inconsistente.

Se bem que a região pareça culturalmente distante, está provavelmente muito mais próxima do que a realidade africana, que se encontra atrás e cuja pressão demográfica atinge seus países, tendo se tornado em um amortecedor de interesses. Sua estabilidade é de grande interesse para a Europa, embora seu nível de desenvolvimento seja baixo (no Índice de Desenvolvimento Humano de 2011, a Tunísia ocupava o posto 94, Argélia o 96, Marrocos o 130 e Mauritânia o 159 em uma lista de 187 países).

A área é caracterizada pela rivalidade entre Marrocos e Argélia, originada depois da independência deste país e levando a uma guerra cruel, a Guerra das Areias. Historicamente, a soberania não era um conceito territorial, mas pessoal e variável, ligado à tribo desdobrada num território, com uma tradicional cerimônia anual de homenagem, a beia, na qual esse reconhecimento era ritualizado. Bled Makhzen aqueles que aceitavam a autoridade do sultão e bled siva aqueles que não.

Se Marrocos (que nunca foi ocupado pelos otomanos) exalta os Almorávides, Argélia fala de Yugurta e Masinissa; ambos os países mantêm as fronteiras fechadas, como só acontece no mundo entre as duas Coréias. Atores internacionais na zona combinam uma relação preferente com um e complementar com o outro.

A questão do Saara Ocidental, em poder do Marrocos desde 
1975 no contexto do conflito Este-Oeste, faz parte dessa lógica, a do Grande Magreb, reivindicado por Allal Al Fassi e construído a partir desse país; o processo de mediação continua buscando um referendo de autodeterminação que parece cada vez mais distante, enquanto o Marrocos segue levando 36 anos de controle sobre a região. As possessões espanholas no Norte da África e até mesmo as Ilhas Canárias têm sido objeto de reivindicação por parte do Marrocos.

Há também a questão berbere, etnia distribuída em toda a área, e que em algum momento da História foi usada para dividir os magrebes; atualmente, com suas tensões, esse problema parece resolvido, mas pode ressurgir em torno do Rif ou da Cabília argelina.

Os grandes espaços vazios do Saara têm sido ocupados pela franquia da Al Qaeda na região, protegida pelas redes tribais e pela imensidão de um vasto deserto na área do Mali, da Mauritânia e da Argélia, que, por si só, torna inoperante o fraco poder desses Estados.

Com relação ao regime interno dos Estados, a aceleração das reformas democráticas empreendidas pelo Marrocos em 2011 e a incorporação ao poder dos islâmicos moderados (Partido da Justiça e Desenvolvimento), juntamente com a legitimidade histórica e religiosa de seu Rei, têm conseguido moderar a resposta da população e ampliar a base social do regime que, por outra parte, conta com a legitimidade outorgada pelo crescimento econômico dos últimos dez anos (a pobreza diminuiu de 16,2\% para 9\% nesse período, com um crescimento notável das infra-estruturas básicas). Ficam atrás os turbulentos anos de chumbo; essa crise é bem distinta.

No caso da Argélia, cabe recordar que o país sofre uma década de conflito armado (não se pode falar propriamente de uma guerra 
civil, pois não houve um controle permanente de uma porção do seu território), com aproximadamente 200.000 mortos, sem que tenha se acabado por completo; a memória de sangrentos massacres de civis, à base de machados e facas, assim como as denúncias de excessos pelos corpos e forças de segurança, ainda estão presentes. Cabe lembrar também as várias anistias e o processo de reconciliação nacional, cuja eficácia tem sido questionada pelo retorno à violência de alguns daqueles que se beneficiaram dos indultos.

O sistema político argelino tem permitido a participação de islâmicos moderados e os incorporou ao poder, onde as Forças Armadas têm muito peso. As estruturas de governo passaram por um processo de re-islamização em resposta às demandas sociais.

O crescimento econômico dos últimos anos, decorrente do processo de liberalização dos anos 80 , contribuiu para a legitimidade do regime e se assenta nos elevados preços do petróleo e de seus derivados (97\% das exportações e 30\% do PIB), permitindo políticas que têm diminuído a efervescência social (se reduziram impostos e também tarifas sobre alguns produtos básicos) e o desenvolvimento de infra-estruturas; as reformas (abolição do estado de emergência, nova lei eleitoral e de partidos) e o cansaço de uma década de violência têm sido uma vacina enfraquecedora da primavera.

Mauritânia é um Estado heterogêneo tribal e frágil, que tem dificuldades em assumir o controle total do seu território, um vasto espaço desértico (três quartos do país) entre o Saara e o Sahel, ponte natural entre os árabes berberes e os negros, em parte colonizada por grupos criminais e terroristas de diferentes tipos (por exemplo, tráfico de cocaína procedente do Golfo de Guiné, tráfico de armas, tráfico 
humano e seqüestros) e de venda, que se aproveitam das "brechas de vizinhança" das quais já se comentou. Isso, juntamente com a descoberta de campos de petróleo offshore, tem atraído a atenção da comunidade internacional, interessada em sua estabilização.

Desde a independência, o país tem sofrido uma sucessão de golpes de Estado e de governos militares; estes estão de volta ao poder depois de umas eleições muito contestadas, que têm diminuído a estrutura institucional do regime. Problemas étnicos permanecem entre os árabes berberes, os maures e os negros africanos (e até mesmo casos documentados de escravidão), que já foram fonte de violência para aquilo que se chama de causa dos processos de arabização e islamização empreendidos.

$\mathrm{Na}$ Tunísia, a primavera árabe começou causando a queda do presidente Ben Ali (que anos antes tinha dado um golpe de Estado médico contra o seu predecessor Bourguiba, como aconteceu com Ludwig II da Baviera); a vitória eleitoral (em um processo modelo, referência para outros países em situações similares) do moderado partido islâmico Ennahda, o Renascimento, que pretende se inspirar no modelo turco (o moderado AKP, Partido da Justiça e do Desenvolvimento, o mesmo nome que o partido marroquino), tem sido até agora o ponto culminante desse movimento, causado pela efervescência social resultante da crise econômica que o país enfrenta.

O Estado líbio, com uma fraca coesão herdada das arbitrárias fronteiras coloniais, foi capaz de se tornar um Estado rentista, dependente dos hidrocarbonetos, com que subsidia a sociedade, ou melhor, as 140 tribos (três delas com autêntico poder decisório) que a integram; isso, juntamente com a gestão dos códigos religiosos, confe- 
riu legitimidade ao regime. Ambiciosos projetos de unificação como o "Great Man Made River Project", com capacidade para expandir a agricultura irrigada por todo o país, permanecem pendentes para o novo governo.

Gaddafi foi capaz de permanecer no poder nesse complexo cenário desde 1969, com flexibilidade política e conhecimento da situação; assim, promoveu o valor simbólico das referências islâmicas, a fim de reforçar as estruturas do Estado, com um militarismo pan-arábico para resolver o problema da identidade do país e um Estado rentista diretamente relacionado com as autoridades tribais, que se vigiavam mutuamente tratando sempre de prevalecer umas sobre as outras.

Finalmente, os problemas de incompetência e corrupção,juntamente com questões religiosas e de distribuição de benefícios (cerca de um terço da população está abaixo da linha de pobreza, apesar do país ocupar o posto 64 no Índice de Desenvolvimento Humano de 2011), empresários afetados pelas nacionalizações e um Exército que desconfiava de sua liderança trouxeram a alteração desses equilíbrios e a fratura das Forças Armadas.

Esse tipo de mudança não é a primeira vez que ocorre; o problema é que antes não houve precedentes bem sucedidos. Além disso, o regime de Gaddafi, apesar dos progressos e da recente abertura política, havia sido identificado como terrorista, o que de cara tornava muito difícil contar com o apoio internacional, qualquer que fosse seu rival.

Prevêem-se lutas pelo poder no seio do Conselho Nacional de Transição (o assassinato do Chefe de Estado Maior do Conselho e a recusa de dissolução das milícias fazem parte dessa lógica) depois que desapareceu o inimigo comum que unia as diferentes milícias, 
InterAção | 29

rearmadas com arsenais de Gaddafi, cujo controle tanto preocupa o Ocidente nesse estado de anarquia (por exemplo, estima-se em 20 mil os mísseis portáteis superfície-ar em posse das Forças Armadas líbias antes do conflito).

A questão é que quem substitua Gaddafi virá do mesmo "saco" que ele, como se viu nas tristes imagens de Misrata ou nas mortes de prisioneiros suspeitos de serem mercenários por sua cor; as coisas podem mudar, mas não é sensato pensar que muito, já que as soluções partem da mesma cultura e Gaddafi esteve no poder por alguma razão. As transições terão os mesmos defeitos que a maioria dos casos dos regimes anteriores.

\subsection{Oriente Médio}

Oriente Médio é um vespeiro onde convergem três continentes. Falar sobre Oriente Médio é falar, de início, do problema entre israelenses e palestinos, um conflito longo e convulso, fonte de tensão na área, cujo fim não se pode prever; sua permanente oscilação, resultado das forças que convergem e da cultura de barganha dominante, chega paradoxalmente a aborrecer; perde-se o fio da meada, mas sempre é fácil de retomar pelas poucas mudanças reais que acompanham os sucessivos processos de negociação.

Questões recorrentes incluem o direito de retorno dos refugiados, o status de Jerusalém, os assentamentos de judeus nos territórios ocupados, o muro, o problema da água, o reconhecimento do Estado palestino e sua viabilidade... Alguns atores mudaram; o Hamas (Irmãos Muçulmanos, para alguns uma organização terrorista; em qualquer caso, com a primavera árabe, mudaram de tática 
e manifestaram o desejo de entendimento com Israel, cuja existência estão dispostos tacitamente a reconhecer) governa na Faixa de Gaza, enquanto o Al Fatah o realiza na Cisjordânia. A diáspora palestina contamina o resto dos conflitos.

Turquia, como vimos, é outra inevitável referência. $\mathrm{O}$ modelo kemalista turco foi capaz de integrar o laicismo, o Islã, a democracia e o nacionalismo. Mas esse foi um primeiro passo; o segundo era inevitável ao longo do tempo e passava pelo reequilíbrio com os padrões culturais da sociedade.

Assim, em 2002, chegou ao poder, após um processo eleitoral, o AKP, partido de origem islâmica, mas que não faz bandeira do Islã e que tem mantido os eleitores mais religiosos e, simultaneamente, atraído o voto de centro-direita, pois evitou questionar os princípios kemalistas, particularmente o laicismo do Estado, enquanto promovia o controle civil sobre as Forças Armadas, espinha dorsal da organização do Estado.

O resultado tem sido uma lenta e gradual islamização da sociedade e o deslocamento dos centros de poder para fórmulas mais democráticas; todos eles, por sua vez, dão ao partido a legitimidade de serem gestores da mudança e lhes converte em um modelo a seguir; um modelo que, pelos prazos, é de evolução e não de revolução, algo muito diferente do que alguns pretendem. Mas isso não significa que seja uma referência indispensável na marcha à democracia dos países do MENA, que encarna um paradoxo, dadas as dificuldades nas suas relações com os antigos membros de seu império.

Quanto aos conflitos que envolvem a Turquia, há problemas com os curdos e os armênios, que afetam vários países da região. No 
InterAção | 31

Cáucaso, a Armênia ocupou Nagorno Karavaj, território do Azerbaijão, que conta com apoio turco. $\mathrm{O}$ reconhecimento do genocídio armênio no contexto da Primeira Guerra Mundial, que os turcos aceitam, mas não na magnitude de um genocídio, reconhecido apenas como excessos em tempo de guerra, disfarça uma disputa de fronteiras.

A questão das ilhas e do mar territorial é um problema que faz parte do passado conjunto de gregos e turcos, onde também faz parte a questão de Chipre, que no verão de 2012, assumirá a presidência rotativa da União, um país dividido entre comunidades (a ocupação turca do norte de Chipre foi em 1974). A descoberta de petróleo e de gás entre sua costa e a de Israel tornou o confronto mais visível.

O Egito sempre tem sido o farol intelectual do mundo islâmico; do Egito são as principais abordagens do Islã, desde Hassan Al Banna e os Irmãos Muçulmanos a Al Zawahiri e Al Qaeda. Construído em torno do Nilo (com conflitos com Sudão pela distribuição de água), é a ponte entre a África e a Ásia; é também o país muçulmano mais populoso (80 milhões), além dos dois milhões de emigrantes distribuídos em toda a área.

E existe um profundo mal estar social, já que $40 \%$ da população vive abaixo da linha de pobreza, com um enorme setor público (30\% da força de trabalho) sustentada somente pelos baixos salários; o aumento dos preços dos produtos básicos (que chegou em 2010 a 25\% em alguns), juntamente com o precedente da Tunísia, está entre os detonantes da crise atual.

A onda de protestos encenada na Praça de Tahrir levou à queda de Hosni Mubarak (que pretendia transferir o poder para seu filho) e à criação de um Conselho Nacional de Transição, sob liderança 
do Marechal Tantawi, mão direita do General Mubarak; com isso o poder nunca deixou de estar nas mãos das Forças Armadas, a final de contas, a estrutura de maior prestígio de todo o país e profundamente enraizada na vida política e administrativa; elas permaneceram em uma atitude ambivalente até as revoltas estarem bem avançadas, o que lhes deu um prestígio para liderar e mediar a transição à maneira do exército turco.

No entanto, iniciou-se um processo de reforma de três fases, previsto para estar finalizado em 2012, com a eleição de um novo presidente. Os islâmicos souberam aproveitar o processo de mudança e, nas eleições legislativas, os "Irmãos Muçulmanos" (Partido da Liberdade e Justiça) e os salafistas de "Al Nur" (uma excisão radical) foram os dois partidos mais votados, por em cima do setor oficial; isso vai diferenciar o Egito do modelo turco de transição, onde a islamização da sociedade ocorreu sobre um laicismo firme e bem estabelecido.

Estão previstas futuras tensões por questões como o ritmo das reformas, o modelo de governo e a reforma do aparato policial do antigo regime (1.300.000 funcionários). A islamização da sociedade trouxe tensões sobre as minorias não-muçulmanas, especialmente os coptos.

No entanto, é difícil conceber o Egito do marabutismo, do Islã popular, governado a partir de princípios radicais; ele pode fazer com que os partidos islâmicos adotem, pelo menos em curto prazo, posturas mais possibilistas. A radicalização proporcionaria também uma profunda alteração no frágil equilíbrio em que se baseia a paz no Oriente Médio, o que preocupa a comunidade internacional como um todo.

Líbano, país de complexos equilíbrios entre as diversas religiões (institucionais ou não) nele existentes, foi criado como um lar 
para os cristãos tirados da Síria; com o passar do tempo (e também com a diáspora palestina), alterou-se a composição demográfica do país. A debilidade do país permitiu o surgimento da organização Hezbollah que, apoiado pelo Irã e com a legitimidade de sua resistência a Israel durante a invasão de seu território, tem substituído o papel do Estado, oferecendo segurança e serviços básicos, não apenas a xiitas, e formando uma zona de estabilidade e de ordem, apesar de seu radical anti-semitismo.

Outro país afetado pelas primaveras é a Síria, um país de baixa renda (ocupa o posto 119 no Índice de Desenvolvimento Humano de 2011), governado desde 1963, após o fracasso da união com o Egito, pelo Baas, um regime patrimonial de partido quase único. É um partido que se define como nacionalista árabe e socialista, fundado por um cristão e um alauíta ( $70 \%$ da população é sunita, enquanto os alauítas estão no poder), que fez do laicismo e do pan-arabismo sua bandeira. No entanto, esse fato tem conformado, por excluir o plano religioso, uma base de confrontação.

O alinhamento e a doutrinação das Forças Armadas com o governo explicam sua duração no tempo, mas, por outro lado, têm impedido a criação de alternativas em um regime ineficiente. Uma excessiva centralização do governo, que gira em torno das grandes cidades do centro do país, e o peso do componente tribal condenam a sociedade à debilidade, com um limitado sistema de proteção social. A queda de receitas e o previsível esgotamento dos recursos petrolíferos desestabilizaram definitivamente o sistema.

Os primeiros protestos contra um processo, que já causou milhares de mortos, vêm a reboque dos eventos da Tunísia e do Egito. 
Os passos para as reformas têm sido fracos e dados somente quando o governo foi forçado a, tardiamente, realizá-los (como a revogação do estado de emergência em vigor desde 1963; a repressão das manifestações prejudicou a imagem do presidente Asad, até então tido por reformista; enquanto simultaneamente aparecia uma violência religiosa.

Os protestos cresceram em intensidade como também a repressão; a violência se disseminou e se organizou, ameaçando a coesão das Forças Armadas e privando o regime do apoio internacional, mesmo na tensa e frágil situação regional; assim, a ameaça de uma guerra civil se fez presente.

\section{CONSIDERAÇ̃̃ES FINAIS}

Fatores polemológicos são os elementos que fundamentam a origem dos conflitos, que, de forma independente, podem conduzir ou não a um enfrentamento; este poderia ocorrer dependendo da presença de certos catalisadores ou detonantes. Sua existência permite os conflitos e a concentração de vários os tornam mais prováveis, mas não os assegura, embora seja fácil bancar o adivinho a posteriori.

Os conflitos, como todos os fatos que afetam as coletividades humanas, podem surgir em meio a razões difusas, apresentar contornos mal definidos e, geralmente, admitir uma pluralidade de explicações; seus motivos se distanciam muito da simplicidade uni causal, são ou costumam ser de natureza plural e multifacetada.

Por outro lado, a complexidade do conflito leva a tratar cada caso como resultado de circunstâncias especiais que não se repetirão. Da mesma forma, não cabe o extremo oposto, isto é, que exista uma 
lei espacial da qual não se pode escapar. Os conflitos não são fenômenos únicos, mas singulares.

De uma revolução, sabe-se quando começa, mas não se sabe como ou quando termina. A Revolução Francesa levou à forca um rei, para acabar entronizando um imperador. $\mathrm{O}$ processo segue aberto e há quem acredita que em fase incipiente. Se observarmos a diversidade das origens e da história - lembrar que houve quem inscrevesse os acontecimentos de 15-M na Espanha no contexto das primaveras árabes - dos países envolvidos, veremos que pode haver diferentes evoluções; os equilíbrios turcos podem servir de inspiração, mas não de modelo para um mundo tão heterogêneo, especialmente quando seus pontos de partida são bem diferentes.

Além disso, não pode causar surpresa que um movimento inicialmente laico passe a outro de inspiração religiosa, toda vez que este obedeça à sua cultura. A crise de identidade que está por trás deles não é menor do que a crise econômica que os impulsiona e coloca o Ocidente frente às suas próprias contradições.

Assim, seguem abertos os dilemas que levam o apoio a um governo saído das urnas, respondendo às novas exigências de câmbio de grandes setores da população, e a tolerar a criação subsequente de uma área de instabilidade em zonas de alto valor estratégico ou que possam afetar o fornecimento energético.

Nesse contexto, a mudança se torna necessária, além de inevitável. A melhor coisa a se fazer não é apoiá-la, mas dirigi-la, oferecendo uma saída a sociedades sem expectativas, que, às vezes, falam de mais democracia, quando, na verdade, querem dizer mais pão, algo que os regimes recém eleitos dificilmente conseguirão em curto pra- 
zo, prejudicando sua legitimidade. É prematuro e voluntarista apresentar esse processo como uma nova onda de democratização.

O progresso não implica em uma moralidade superior, mas em níveis mais altos de contradição interna. A chegada ao poder dos radicais pode também situá-los frente às suas próprias contradições; entre suas crenças e a necessidade de atender às demandas reais da população, aceitando sua concepção religiosa. Estes países não podem viver à margem do Ocidente em um mundo que foi dobrado sobre si mesmo; ninguém é uma ilha, nem mesmo por vontade própria. Portanto, os fluxos econômicos que do exterior financiam o radicalismo extremo devem ser controlados.

A solução para todos os problemas reside no fortalecimento do Estado e em torná-lo adequado à sociedade em que se instala, enquanto satisfaz suas demandas. O Estado está para a sociedade e não o inverso; o outro é, na melhor das hipóteses, transitório e se chama ditadura. Em qualquer caso, a necessidade de mudança não pode ignorar a realidade do que foi conseguido até agora.

A geografia e a globalização obrigam-nos a compartilhar o destino. Somos forçados a conviver e a nos relacionar. Como disse D'Ors "Uma e outra vez se foram sucedendo no dominio daquele mar, uns e outros povos, umas e outras esquadras, mas o mar seguia sendo para todos o Mar nosso". 